\title{
REFLEXÕES SOBRE O PREPARO DO ENFERMEIRO NA ÁREA DE ONCOLOGIA PEDIÁTRICA*
}

\author{
Luciana Pagano Castilho Françoso
}

FRANÇOSO, L.P.C. Reflexões sobre o preparo do enfermeiro na área de oncologia pediátrica. Rev. Latino-am.enfermagem, Ribeirão Preto, v. 4, n. 3, p. 41-48, dezembro 1996.

A questão do preparo profissional em Enfermagem Oncológica Pediátrica é discutida, inicialmente através de reflexões sobre o tema da morte e posteriormente através de reflexões sobre os aspectos críticos da assistência na área, ligados à relação enfermeira-paciente.

UNITERMOS: preparo profissional do enfermeiro, câncer infantil

\section{Vida e morte na assistência à criança com câncer}

As questões relativas à vida e à morte ganham um delineamento especial quando se trata de vislumbrá-las nos contextos construídos e organizados para atender as necessidades e problemas humanos relacionados à saúde e à doença.

Muito tem se falado a respeito dos problemas existentes em torno das questões relacionadas à morte. Estudiosos e pesquisadores de diversas áreas do conhecimento têm abordado o tema sob variados pontos de vista, na tentativa de lançar luz sobre as formas pelas quais a morte é representada e enfrentada pela Sociedade Ocidental atual ${ }^{* *}$.

\footnotetext{
* Artigo inspirado na dissertação apresentada à Escola de Enfermagem de Ribeirão Preto da Universidade de São Paulo, para obtenção do grau de mestre, sob a orientação da Profa ${ }^{2}{ }^{a}$ Elizabeth Ranier Martins do Valle (FAPESP)

** O tema da morte no campo das ciências humanas tem sido amplamente explorado nas últimas décadas, e é significativa a extensão das referências bibliográficas estrangeiras e nacionais relativas a esta questão. É de grande interesse a lista de referências organizada por TORRES e colaboradores 16, a despeito de não incluir as inúmeras contribuições da última década
} 
Complexos processos históricos, culturais e psicológicos são reconstruídos no intuito de compreender como as questões ligadas à morte foram silenciadas e negadas, tornando-se mesmo um tabu, assunto banido da vida cotidiana. KOVÁCS ${ }^{10}$ retoma em seu trabalho alguns destes processos, e afirma um possível fundamento da interdição das questões ligadas à morte em nossa época: "A sociedade atual expulsou a morte para proteger a vida" (KOVÁCS ${ }^{10}$, p.81).

Vida e morte são dissociadas, para que em seu desencontro com a morte o homem encontre a vida. Pensá-la de forma integrada representa uma ameaça difícil de ser suportada.

No tocante a esta questão, os profissionais de saúde que, cotidianamente convivem com a doença, o sofrimento e a morte, desenvolvem maneiras peculiares de enfrentar tal ameaça. São conhecidas e amplamente estudadas as reações mais freqüentes de tais profissionais, sendo que os estudos abordam desde questões da formação até problemas a nível pessoal e institucional decorrentes do contato com a morte $^{4,5,7,8,9}$.

De qualquer modo, fica evidente a insuficiência presente na área da saúde para o trato das questões ligadas à morte.

Geralmente, os profissionais são formados e preparados para lidar com a doença e o sofrimento - inerentes a qualquer contexto de prestação de serviços na área da saúde - de uma maneira irrealista e idealizada. A ênfase na cura enquanto finalidade única e a crença na onipotência da tecnologia moderna dificultam o enfrentamento das situações vividas cotidianamente nas instituições assistenciais. Vale ressaltar que muitos são os profissionais da área da saúde preocupados com esta temática. $\mathrm{Na}$ área da Enfermagem, BOEMER ${ }^{2}$ lançou luz sobre aspectos importantes relacionados às questões ligadas à morte através do desenvolvimento de seus estudos, além de mostrar como é possível a inclusão do tema na formação do profissional de saúde.

Especificamente na área do câncer infantil, a morte eclode no cotidiano da assistência, e não há como ocultá-la. Ocorre, então, uma espécie de afastamento da vida: a morte invade todos os espaços, e sua onipresença implícita ou explícita detona angústias difusas e paralisantes. Afasta-se a vida com o mesmo objetivo pelo qual afasta-se a morte: para preservá-la. Através do afastamento de uma ou de outra, mantém-se a distância necessária à perpetuação da dissociação.

Acresce-se a esta situação o processo de idealização que envolve a infância. Fonte de expectativas positivas e prazerosas representa comumente a corporificação da vida $^{12}$. Tal processo é minado e é fortalecida a necessidade de manter a vida intacta e protegida - em outro local que não seja o cotidiano sofrido e doloroso da criança com câncer.

Assim múltiplas manifestações possíveis da morte se revelam. A impotência diante da criança doente, a sensação de insuficiência, a constante expectativa de morte, a descrença em relação às medidas terapêuticas disponíveis, são, no fundo, uma espécie de paralisia diante da realidade e de suas demandas. Tal paralisia 
decorre da angústia suscitada pela percepção de que o câncer pode levar a criança à morte, a despeito dos esforços efetuados.

Ora, a questão é que o câncer pode efetivamente levar a criança à morte, mas nem sempre. Mesmo quando isto ocorre, é preciso investir na vida enquanto há vida: atentando para as necessidades globais da criança e procurando atendê-las na medida do possível.

Vale lembrar que esta paralisia é intensificada por outras manifestações possíveis da morte, decorrentes das características mais freqüentes das instituições de saúde: as rotinas burocratizadas e automáticas, o mecanicismo das ações, a impossibilidade de incluir no dia a dia o complexo mundo dos sentimentos, desejos e necessidades envolvidas nas relações. A morte se manifesta também no silenciamento que a organização da instituição impõe à criatividade dos profissionais responsáveis pela assistência, na rigidez das hierarquias e estabelecidas, na negação dos conflitos inerentes à vida.

Há necessidade, portanto, do resgate da vida - com suas possibilidades e limitações, através da percepção do sentido da assistência na área do câncer infantil. Este sentido só pode ser percebido através de uma filosofia de trabalho baseada numa postura de constante abertura e consideração da realidade conforme ela se manifesta - em sua multiplicidade.

Assim, há necessidade de que espaços sejam estabelecidos na rotina da instituição, para que neles os profissionais possam falar, ouvir e serem ouvidos. É importante que troquem experiências, compartilhem seus sentimentos e dificuldades, pensem sobre suas ações a avaliem continuamente as possibilidades e limites de si próprios e do contexto no qual estão inseridos. Assim, talvez possam vislumbrar o sentido de seus trabalhos e participara ativamente da construção de uma assistência que se aproxime das necessidades reais das pessoas assistidas.

\section{A relação entre o profissional de saúde (a enfermeira) e o paciente (a criança com câncer e sua família) - a comunicação, o envolvimento e o atendimento das necessidades emocionais.}

Em pesquisa realizada junto a enfermeiras atuantes na área da Oncologia Pediátrica ${ }^{6}$, estas apontam áreas consideradas críticas em seus trabalhos, o que pode ser utilizado como subsídio para o delineamento de um preparo adequado.

Estas áreas críticas dizem respeito principalmente a aspectos da relação entre enfermeira e paciente. Há questionamento e dificuldades no que se refere à comunicação, ao envolvimento e ao atendimento das necessidades emocionais da criança e de seus familiares.

Vieram à tona, de forma significativa, questões referentes à comunicação entre a enfermeira e o paciente com câncer. Foram feitas comparações entre bebês, crianças, adolescentes e adultas, levando-se em conta o que cada um expressa verbalmente a respeito do que está vivendo. Parece que esta expressão influencia 
o tipo de envolvimento que se configura com a enfermeira. O envolvimento emocional é mais significativo quando o paciente expressa suas idéias e sentimentos de forma compreensível para a enfermeira, e esta parece compreender com maior facilidade a linguagem verbal, mais especificamente a fala adulta.

As crianças maiores e os adolescentes provocam maior incômodo e sofrimento porque falam sobre o que vivem em decorrência da doença e do tratamento. Os bebês e as crianças menores, por não expressarem-se verbalmente com a mesma clareza, são considerados mais fáceis de serem cuidados, por não demandarem esforço emocional na mesma intensidade que os pacientes que expressam-se através da fala. Assim, a expressão verbal é tomada como referência, capaz de modular afetivamente as relações estabelecidas e direcionar a atuação da enfermeira.

Uma vez que nos currículos de graduação em Enfermagem há tópicos específicos sobre a comunicação, penso que seria útil para a enfermeira a possibilidade de retomar o conhecimento de que há múltiplas formas de linguagem possíveis. A linguagem verbal é apenas uma destas formas, e por ser a mais usada e valorizada pelos adultos de nossa cultura ocidental é muitas vezes a única observada e compreendida. Os bebês e as crianças utilizam-se de uma gama mais ampla de recursos para comunicarem suas necessidades físicas e emocionais seus próprios corpos, seus atos e comportamentos, constantemente comunicam algo aos adultos que os cercam****.

O reconhecimento destas e de outras formas de linguagem no dia a daí de seu trabalho propiciaria a enfermeira uma ampliação da compreensão das situações vividas pelos pacientes e por ela mesma. Isto, sem dúvida, enriqueceria sua atuação e contribuiria para a adequação da assistência às necessidades reais das pessoas nela envolvidas.

Quanto ao envolvimento é importante retomar o conceito de "distância crítica" elaborado por SCHAVELZON ${ }^{15}$. O autor, referindo-se à relação entre médico e paciente com câncer, aponta a possibilidade de uma atitude profissional evitativa e distante, o que denominou "a grande distância". Caracterizada pelo privilegiamento dos aspectos orgânicos e físicos dos problemas dos pacientes, baseia-se no reconhecimento apenas intelectual de suas vivências. Aponta também a possibilidade de uma atitude profissional participante e comprometida, caracterizada pela proximidade excessiva e invasiva, assim como pela supervalorização dos aspectos, emocionais dos problemas dos pacientes.

Tais atitudes são, na realidade, reações extremas a um mesmo fenômeno: o profissional viver, sofrer e se identificar com o paciente de uma tal forma que fica

\footnotetext{
*** Inúmeros autores da área de Psicologia descrevem de forma clara e didática esta questão, dentre eles: Helen Bee em A criança em desenvolvimento (Ed. Haper \& How do Brasil Ltda. Sp, 1984) e Rappaport e colaboradores na coleção Psicologia do desenvolvimento (EPU, SP, 1981)
} 
impossibilitado de discernir o que é seu e o que é do outro. Torna-se assim, difícil estabelecer a "distância crítica" necessária - o que permitiria a manutenção de sua capacidade terapêutica e operativa enquanto profissional.

Diante desta questão, SCHAVELZON ${ }^{15}$ conclui que não há uma solução que possa ser regeneralizada no tocante a este problema. Não há, em outras palavras, uma "receita geral" de como encontrar esta "distância crítica". No entanto, sugere algumas medidas que podem ser úteis: o reconhecimento, por parte do profissional, de suas características enquanto ser humano; o discernimento de seus problemas dos problemas do paciente; a constante troca entre ambos, através de uma escuta, atenta.

As enfermeiras ouvidas no trabalho mencionado ${ }^{6}$ evidenciam atitudes similares às estudadas por SHAVELZON ${ }^{15}$. Afastando-se, aproximando-se excessivamente, transcendendo ou acolhendo a realidade do câncer infantil, manifestam distâncias possíveis em suas relações com a criança doente e seus familiares. Em alguns momentos alcançam a "distância crítica" necessária à realização de seus trabalhos de modo efetivo; em outros se perdem em seus próprios movimentos.

O sofrimento associado ao câncer muitas vezes é da própria enfermeira, cujos medos em relação à doença (e à morte) são mobilizados por suas relações com a criança. Suas atitudes visam, muitas vezes, atender a si próprias, não às necessidades do paciente que cuidam.

Um outro aspecto que merece atenção é a questão do atendimento das necessidades emocionais da criança e de sua família. Diante da percepção de que a assistência e o cuidado devem transcender os procedimentos técnicos, as enfermeiras tendem a dirigir suas ações no sentido de resolver os problemas suscitados pela prática utilizando critérios pouco claros e definidos, muitas vezes baseadas no senso comum.

Um exemplo é a comum valorização do apoio ao paciente e sua família, recurso utilizado com o objetivo de aliviar o sofrimento trazido pelos problemas decorrentes da doença e do tratamento.

Conforme ressalta BALINT ${ }^{1}$, em seu importante estudo sobre a relação médico-paciente, o conselho, o apoio, o conforto não têm em si nada de mal. Podem, efetivamente, ser armas terapêuticas poderosas. É negativo o fato do profissional os administrar ao acaso, sem avaliar apropriadamente seus prováveis efeitos em cada caso particular. O autor denomina "função apostólica" do exercício da profissão médica, as ações dirigidas pelo senso comum do profissional, que em seu "furor terapêutico" tenta aliviar o sofrimento do paciente a qualquer custo, utilizando para isto os recursos que lhes são disponíveis.

Assim, seria apropriada uma atenção especial no tocante a esta questão junto às enfermeiras. Talvez possam atender às necessidades emocionais dos pacientes e de seus familiares munidas de um referencial teórico e técnico que lhes permita uma atuação mais eficaz do ponto de vista assistêncial e mais segura do ponto de vista profissional. 
$\mathrm{BALINT}^{1}$ refere-se à necessidade do profissional aprender a ouvir - a si próprio e ao paciente. Só quando é capaz de diagnosticar a situação que se apresenta com clareza, pode fazer uso da terapêutica indicada para cada caso particular em questão.

Vários outros autores, assim como SCHAVELZON ${ }^{15}$ e BALINT ${ }^{1}$, abordando as relações entre profissional de saúde e paciente enfatizam a importância de saber ouvir - tanto a si próprio como ao paciente ${ }^{3,12,13}$.

Quando o profissional é capaz de ouvir a si próprio e ao outro, pode identificar as múltiplas necessidades emergentes nas situações nas quais se desenvolve a assistência com discernimento e clareza. Pode, então, avaliar as possibilidades e limitações quanto ao atendimento destas. Quando o profissional não é capaz desta escuta, pode aprender: há conhecimentos e técnicas que podem auxiliá-lo a desenvolver e treinar adequadamente tal habilidade.

Nesta discussão é importante ressaltar o papel das medidas educativas e do conhecimento teórico no preparo dos profissionais de saúde atuantes na área da Enfermagem Oncológica Pediátrica. Este tipo de preparo, iniciado em nível da graduação, deve oferecer uma visão ampla acerca da saúde e da doença, enfatizando a necessidade da abordagem multidisciplinar das questões desta ordem. A continuidade de tal preparo em nível das instituições de saúde é imprescindível para que os conhecimentos sejam retomados e redimensionados. A realização de cursos, seminários, palestras e discussões deve ser parte integrante das rotinas dos serviços.

O planejamento de eventos desta ordem deve ter como orientação básica as características específicas do serviço em questão e as demandas próprias dos profissionais aos quais são dirigidos. Os temas abordados, assim como a forma de abordá-los, só têm repercussão junto aos profissionais se tiverem real proximidade com sua prática, abrangendo seus questionamentos e necessidades. Caso contrário, correm o risco de transformar-se em discurso vazio inútil, e em nada poderão contribuir para a assistência prestada.

Em síntese, penso que fica clara a necessidade de um preparo contínuo, que faça parte de rotina de trabalho dos profissionais de saúde atuantes na área da Enfermagem Oncológica Pediátrica. Este preparo deve se dar tanto através de medidas educativas e aprimoramento de conhecimento técnico-teórico, quanto através da atenção e consideração dos aspectos das relações humanas desenvolvidas no contexto institucional. A forma de incluir este preparo na rotina deve relacionar-se intimamente à realidade do serviço de saúde em questão, mas remete necessariamente a saberes e práticas de outros campos de conhecimento além das Ciências Biomédicas. LIMA ${ }^{11}$ aponta com clareza como o modelo de assistência clínico, individual, curativo, hospitalar e tecnicamente sofisticado é ineficaz na área da Oncologia Pediátrica e pode ceder espaço a um novo modelo com a inclusão do trabalho em equipe multiprofissional, mais capaz de compreender a criança com câncer em sua especificidade, com determinações familiares, ambientais, emocionais e culturais. 
A contribuição da Psicologia no tocante a estas questões é importante. A Psicologia, em quanto saber e prática, traz a possibilidade de lançar luz sobre aspectos fundamentais da assistência na área da saúde. Tais aspectos dizem respeito à dimensão do sentido das experiências vividas para seus sujeitos; à dimensão dos desejos, afetos e significados que permeiam as relações construídas no contexto institucional; à dimensão da subjetividade.

Não há como considerar esta dimensão psicológica sem antes conhecê-la. Seu conhecimento, além de evidenciar sua importância, aponta caminhos para sua utilização enquanto recurso para construção de uma assistência que satisfaça as necessidades e demandas que justificam sua existência.

\section{REFLECTIONS ABOUT PROFESSIONAL PREPARATION IN ONCOLOGYPEDIATRIC NURSING}

The question of professional preparation in Oncologic Nursing is discussed, at first through reflections about the theme of death and after through reflections about critical aspects of the care in the area related to nurse-patient relationship.

UNITERMS: nursing professional preparation, childhood cancer

\section{REFLEXIONES SOBRE PREPARACIÓN DEL ENFERMERO EN LA ÁREA DE ONTOLOGÍA PEDIÁTRICA}

La cuestión de la preparación profesional en Enfermería Oncológica Pediátrica es discutida inicialmente a través de reflexiones sobre el tema de la muerte y posteriormente a través de reflexiones sobre aspectos críticos en la asistencia en la área, ligados a la relación enfermera-paciente.

TÉRMINOS CLAVES: preparación profesional del enfermero, cáncer infantil

\section{REFERÊNCIAS BIBLIOGRÁFICAS}

01. BALINT, M. O Médico, seu paciente e a doença. Trad. de Roberto Musachio. Rio de Janeiro: Atheneu, 1988. 331p. 
02. BOEMER, M.R. O fenômeno morte: o pensar, o conviver, e o educar. Ribeirão Preto, 1989. 111 p. Tese (Livre-docência) - Escola de Enfermagem de Ribeirão Preto, Universidade de São Paulo.

03. CASSORLA, R.M.S Aspectos psicológicos da relação médico-paciente com câncer. Estudos de Psiclogia, v. 1, p. 48-62, 1983.

04. CONCONE, M.H.B. O "vestibular" de anatomia. In: MARTINS, J.S. A morte e os mortos na sociedade brasileira. São Paulo: Hucitec, 1983. Cap. 2, p. 25-37.

05. CONSORTE, J. A morte na prática médica. In: MARTINS, J.S. A morte e os mortos na sociedade brasileira. São Paulo: Hucitec, 1983. Cap. 3, p. 38-57.

06. FRANÇOSO, L.P.C. Enfermagem: imagens e significados do câncer infantil. Ribeirão Preto, 1993. 145 p. Dissertação (mestrado) - Escola de Enfermagem de Ribeirão Preto, Universidade de São Paulo.

07. FERREIRA SANTOS, L.A. Os profissionais da saúde enfrentam-negam a morte. In: MARTINS, J.S. A morte e os mortos na sociedade brasileira. São Paulo: Hucitec, 1983. Cap. 1, p. 15-24.

08. HOFFMANN, L.M.A. Os médicos e a morte na infância: a representação de um tema interditado. Rio de Janeiro, 1991. 115 p. Dissertação (Mestrado) Instituto Fernandes Figueira, Fundação Oswaldo Cruz.

09. KOVÁCS, M.J. A questão da morte e a formação do psicológico. São Paulo, 1989. 221 p. Tese (Doutorado) - Instituto de Psicologia, Universidade de São Paulo.

10. Pensando a morte e a formação de profissionais de saúde. In: CASSAROLA, R.M.S. (coord.). Da morte: estudos brasileiros. Campinas: Papirus, 1991. cap. 4, p.79-103.

11. LIMA, R.A.G. O processo de trabalho da Enfermagem na assistência a criança com câncer: análise das transformações em um Hospital-Escola. Ribeirão Preto, 1990. 124 p. Dissertação (Mestrado) - Escola de Enfermagem de Ribeirão Preto, Universidade de São Paulo.

12. MELLO FILHO, J. Concepção psicossomática: visão atual. 5a ed. Rio de Janeiro: Tempo Brasileiro, 1988. 215 p.

13. PERESTRELLO, D. A medicina da pessoa. $4^{\text {a }}$ ed. Rio de Janeiro: Atheneu, 1989. $272 \mathrm{p}$.

14. SALES, L.M.M. A negação do mal: as idéias de infância no imaginário adulto. Um processo de idealização. São Paulo, 1992. 132 p. Dissertação (Mestrado) Pontifícia Universidade Católica de São Paulo.

15. SCHAVELZON, J. El concepto de "Distancia Critica" el la relación médico-paciente con cáncer. In: SCHAVELZON, J. et al. Cáncer: enfoque psicológico. Buenos Aires: Galern, 1978. P.69-74.

16. TORRES, W.C. et al. (coord.) A psicologia e a morte. Rio de Janeiro: Fundação Getúlio Vargas, 1985. 135p. 